Journal of Electronics and Informatics (2019)

Vol.01/ No. 02

Pages: $107-116$

http://www.irojournals.com/iroei/

DOI: https://doi.org/10.36548/jei.2019.2.006

\title{
MIMO BASED HIGH SPEED OPTICAL FIBER COMMUNICATION SYSTEM
}

\author{
Dr. P. Karuppusamy, \\ Professor, \\ Department of EEE, \\ Shree Venkateshwara Hi-Tech Engineering College, \\ Erode, India. \\ Email id: pkarrupusamyphd@gmail.com
}

\begin{abstract}
As the telecommunication services totally relies on the optical fiber for extending communications, it necessary that the optical communication system be capable of handling high speed, multiple channels and long haul signal transmission. recently the emergence of the optical coherent $100 \mathrm{~GB} / \mathrm{s}$ and the digital signal processing has made possible the perfect signal transmission even for the MIMO (multiple input multiple output system) as they are well reformed to permit multiple wireless signal that holds different carrier frequencies. So the optical fiber system has become prominent among the applications like, large universities, banks and other private networks. However the speed in the transmission of the multiple wireless signals through single cable experiences performance issues in terms of speed, so the proposed method utilizes the $60 \mathrm{GHz}$, radio over fiber MIMO with effective spectrum allocation and the return zero differential phase shift keying to improve the communication speed and suppress the crosstalk respectively. The proposed system enriches the seamless communication with the QPSK-OFDM MIMO channels achieving $85 \%$ in the data transmission rate, reducing the error correction rate to $5 \%$.
\end{abstract}

Keywords: Optical Fiber Communication, Multi Input and Multi Output channels, QPSK, OFDM, Spectrum allocation

\section{INTRODUCTION}

The expectations of the man are increasing day by day as the changes in the technology are progressing at a rapid pace. His search for improving the way and the quality of living has been the key to tremendous advancements in techniques that support the information sharing as well as the social communication. These advancements have made possible the affordable wireless communication services in reality and have also enabled a seamless communication. The telecommunication service today completely relies on the optical fiber system as they provide highly reliable, very high speed, long haul multi-channel signal transmission.

ISSN: 2582-3825 (online) 
Journal of Electronics and Informatics (2019)

Vol.01/ No. 02

Pages: 107-116

http://www.irojournals.com/iroei/

DOI: https://doi.org/10.36548/jei.2019.2.006

\subsection{OPTICAL FIBER COMMUNICATION}

The optical fiber serve as fundamental block in the telecommunication network, and appears to be ultimate for transmission rate beyond gigabits due to the low attenuation and high bandwidth along with the information carrying attributes and capabilities respectively. Initially the optical fiber communication system was put in use for carrying out telecommunication services among their respective countries and nowadays it is used in much application that requires a reliable system to convey the PC and also the financial information. The communications using the optical fiber is carried out by establishing optical connections utilizing the optical modulation (OM), in which the information to be transmitted is modulated over the instantaneous power of the carrier employing the direct detection for the down conversion technique (DT) at the receiver end. So the information conveyed would be the optical power from the emitter at a particular instant and the information received would be the photo detectors instantaneous current at the receiver. Following the procedure the optical channel employed with OM and the DT is structure as a baseband linear system supported with impulse response. The conventional optical fiber system is represented below in figure.1

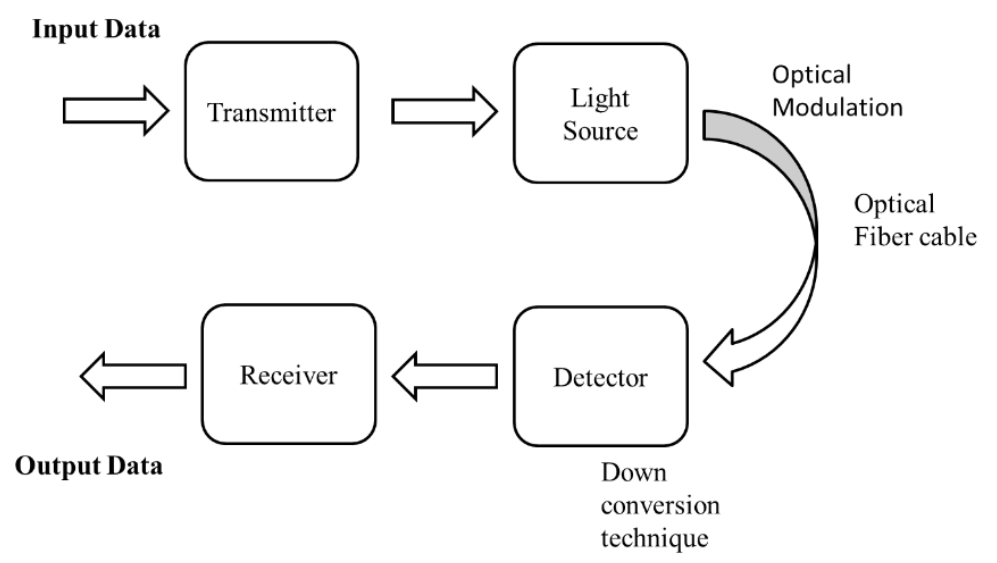

\subsection{MULTI-INPUT AND MULTI-OUTPUT TECHNIQUES (MIMO)}

The increased demands in the data transmission rates and the simultaneous increase in the bandwidth of the allotted radio channels, has paved way for the multi-input and the multi output wireless systems, it is a system enriched with the multi-antenna for the process of conveying, the performance of the MIMO in terms of the transmission range, transmission rate and link reliability are very high when compared to the single input single output techniques. The MIMO would be opted by systems that require high throughput and increased transmission range. The MIMO is 
Journal of Electronics and Informatics (2019)

Vol.01/ No. 02

Pages: $107-116$

http://www.irojournals.com/iroei/

DOI: https://doi.org/10.36548/jei.2019.2.006

categorized into three types and the table. 1 below provides the different types of the MIMO system and their frame work.

\begin{tabular}{|c|c|}
\hline MIMO -TYPES & DESCRIPTION \\
\hline MIMO 1 & $\begin{array}{l}\text { Enables spatial diversity and enhances power efficiency. } \\
\text { Includes the space-time/frequency block code, space-time trellis code and } \\
\text { the delay diversity. }\end{array}$ \\
\hline MIMO 2 & $\begin{array}{l}\text { - Implements spatial multiplexing, } \\
\text { - Increases transmission rate } \\
\text { - Independent data streams are conveyed using cluster of antennas } \\
\text { are recovered. }\end{array}$ \\
\hline MIMO 3 & $\begin{array}{l}\text { - Achieves capacity gain } \\
\text { - Preprocess the signals that are to be transmitted and decodes the received } \\
\text { signal based on the count of the transmitted and the received signals. }\end{array}$ \\
\hline
\end{tabular}

Table.1 MIMO TYPES

Though the optical fiber system is very prominent among the multitude of communication system and capable of achieving high throughput and transmission range, the speed of the system remains very low when multiple wireless signals are transmitted through the single cable following an up conversion technique. So the paper tries developing a proposed system that utilizes the $60 \mathrm{GHz}$, radio over fiber MIMO with effective spectrum allocation and the return zero differential phase shift keying to improve the communication speed and suppress the crosstalk respectively.

The paper is organized with the 2. Providing the literature survey on the ground works performed to develop the proposed system, 3. Providing the details of the proposed scheme, 4 provide the details of the results observed and 5. The concluding part providing the summary of the work carried out.

\section{LITERATURE SURVEY}

ISSN: 2582-3825 (online) 
Journal of Electronics and Informatics (2019)

Vol.01/ No. 02

Pages: 107-116

http://www.irojournals.com/iroei/

DOI: https://doi.org/10.36548/jei.2019.2.006

The optical fiber communication is more prominent in the telecommunication system due to tits data transmission capacity, high bandwidth and low attenuation; it is more preferred in today's data communication due to its reliability. The literature survey presents the details of the MIMO based optical fiber application. The author Al Amin, Abdullah et al [1] has framed a "Dual-LP 11 mode 4x4 MIMO-OFDM transmission over a two-mode fiber." to provide a multiple input and multiple output transmission using the OFDM, the author Lee, Jong-Hun et al [2] puts forth the "Access point for constructing optical fiber-based high-speed wireless network system." Using the optical fiber cables.

Hsu, Rick CJ et al [3] presented the "Capacity enhancement in coherent optical MIMO (COMIMO) multimode fiber links." The author Fan, Shu-Hao et al [4] proposes the "Spectrally efficient 60-GHz xy-MIMO data transport over a radio-over-fiber system for gigabit wireless local area networks." Shao, et al [5] in his paper presents the "A novel scheme for seamless integration of RZ-DPSK-DWDM optical links with MIMO-OFDM system"

Zhao et al [6] has proposed the "Radio admission control scheme for high-speed railway communication with MIMO antennas." And Kuruvila, Diya et al [7] has presented the "Dynamic Adaptive Topology Control in Highly Mobile Environment." While the author Ananthi, J. Vijitha, et al [8] clearly explains the "A Peer to Peer Overlay Approach for Topology Maintenance in Wireless Networks." The author Jennifer S. Raj et al [9] proposes the detail structure of the "Secure interoperable architecture construction for overlay networks."

S. Smys et al [10] presents the "A novel report on architecture, protocols and applications in Internet of Things (IoT)." And the R. Harikumar puts forth the "A new distributed architecture for connectivity analysis in wireless networks." As well as Dinesh Kumar et al [11] details the . "Trust-based intrusion detection and clustering approach for wireless body area networks." And the Ho, et al [12] proposes the 50-Gb/s radio-over-fiber system employing MIMO and OFDM modulation at $60 \mathrm{GHz} . "$ Whereas Thomsen et al [14] provides the MIMO enabled $40 \mathrm{~Gb} / \mathrm{s}$ transmission using mode division multiplexing in multimode fiber."

\section{PROPOSED WORK}

ISSN: 2582-3825 (online) 
Journal of Electronics and Informatics (2019)

Vol.01/ No. 02

Pages: $107-116$

http://www.irojournals.com/iroei/

DOI: https://doi.org/10.36548/jei.2019.2.006

The proposed work improving the speed in the optical cable while transmitting multiple wireless signals through single cables is categorized into three stages as (i) Up conversion techniques making the transmission through single cable possible, (ii) improving speed utilizing the $60 \mathrm{GHz}$, radio over fiber MIMO with effective spectrum allocation and (iii) suppressing the crosstalk in the system employing the return zero-DPSK.

(i)The up conversion technique utilized in the proposed system is a light weight frequency up convertor, (LiNbO3) modulator. The up convertor produces multiple optical carriers that could be employed in modulating multiple wireless signals in isolated manner with many external intensity modulators. The modulated signal is multiplexed and transmitted along the single optical fiber without any overlap spectral bands that are adjacent. The multiple optical wavelengths from single optical source is generated using the dual arm modulator that is controlled by the sinusoidal clock frequency $f_{m}$, The DA - modulator fine-tunes to produce multiple frequency component among the multiple wavelengths the dominant wavelength is utilized as the down link to transmit the multiple signal over the single optical fiber.

(ii) The previous step includes the steps involved in the generating the multiple carrier frequency and splitting the wave length of the single optical source into multiple wavelengths, this step details the modulation of the information, the pre-coded-OFDM is used in modulating the signal, the pre-coded OFDM is generated including the two different OFDM signals at each point alternatively. The figure. 2 shows the proposed MIMO high speed OFC architecture.

(iii) The cross talks in the system is suppressed employing the return zero - DPSK, by adjusting the optical delay lines the interference in the between the multiple signal transmission is avoided. In the receiving end the information signal are demultiplexed using the clock driven optical switch and the antennas of limited band width are employed as the band pass filters to reproduce the original signals, in case of the mobile users the data is further processed using the digital signal processing and transmitted wirelessly.

ISSN: 2582-3825 (online) 
Journal of Electronics and Informatics (2019)

Vol.01/ No. 02

Pages: 107-116

http://www.irojournals.com/iroei/

DOI: https://doi.org/10.36548/jei.2019.2.006

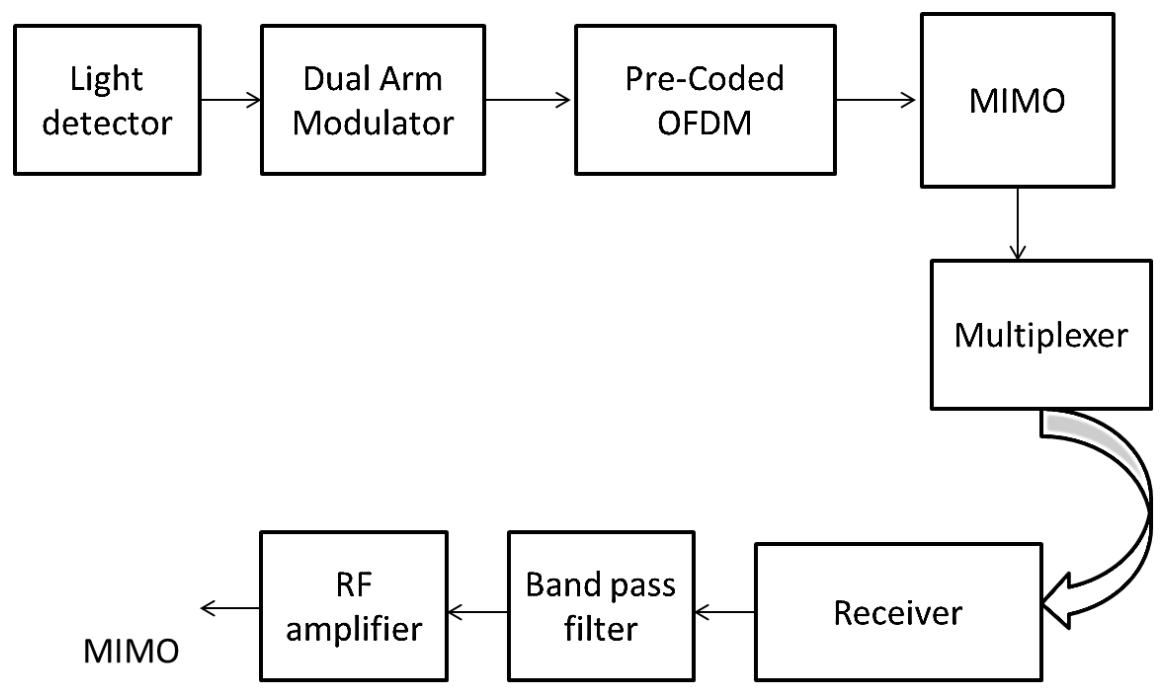

Figure.2 proposed MIMO high speed OFC architecture.

\section{EXPERIMENTAL RESULTS}

The demonstration of the proposed method is performed using three different information's modulated at three different frequencies and conveyed using the single optic fiber cable. The proposed system can be utilized in external applications and can also be implemented in the present system without wasting the money invested previously. The signal are modulated with the frequency of $2.5 \mathrm{GHz}$ to $5 \mathrm{GHz}$ carrier frequency at a data rate of $1 \mathrm{~Gb} / \mathrm{s}$ and the cross talks are suppressed as the signals are presented in the return zero- DPSK format and transmitted using different carrier frequency.

The fig. 3 above shows the optical frequency obtained to transmit the information by the generation of the multiple frequency components the optical frequencies generated are $\left(f_{1}-f_{c}, f_{2}-2 f_{c}, f_{3}-3 f_{c}\right.$ etc $)$ and at the output the optical frequencies obtained are $\left(f_{1}+f_{c}, f_{2}+2 f_{c}, f_{3}+3 f_{c}\right.$ etc $)$ the dominant wavelength are separated using the wave division multiplexing and employed as the down link wave length.

ISSN: 2582-3825 (online) 
Journal of Electronics and Informatics (2019)

Vol.01/ No. 02

Pages: $107-116$

http://www.irojournals.com/iroei/

DOI: https://doi.org/10.36548/jei.2019.2.006

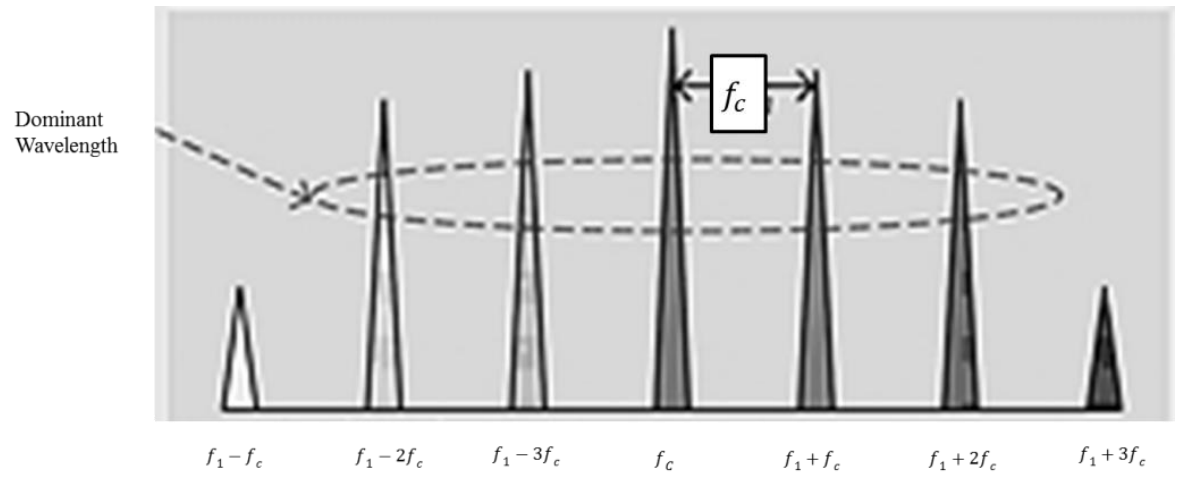

Figure.3 Optical Frequencies Generated from Dual arm Modulator

\begin{tabular}{|c|c|c|c|c|c|c|c|c|}
\hline \multirow{2}{*}{$\begin{array}{l}\text { Optical fiber } \\
\text { cable length } \\
\text { (km) }\end{array}$} & \multicolumn{2}{|c|}{ Launched optical power } & \multicolumn{3}{|c|}{ Received optical power } & \multirow{2}{*}{$\begin{array}{l}\text { Data } \\
\text { Transmission } \\
\text { rates }(\mathrm{MHz})\end{array}$} & \multirow{2}{*}{$\begin{array}{l}\text { Data } \\
\text { Reception } \\
\text { rates }\end{array}$} & \multirow[b]{2}{*}{ Error rate } \\
\hline & $2.5 \mathrm{Ghz}$ & $5.0 \mathrm{GHz}$ & $\begin{array}{l}10^{0} \\
\text { BER }\end{array}$ & $\begin{array}{l}10^{-10} \\
\text { BER }\end{array}$ & $\begin{array}{l}10^{-20} \\
\text { BER }\end{array}$ & & & \\
\hline 40 & $\begin{array}{c}2 \mathrm{~dB} * 10^{-12} \\
\text { BER }\end{array}$ & $\begin{array}{c}2 \mathrm{~dB}^{*} \\
10^{-18} \\
\text { BER }\end{array}$ & -22 & -16 & -10 & 82 & 82 & 2.35 \\
\hline 50 & $\begin{array}{c}4 \mathrm{~dB} * 10^{-10} \\
\mathrm{BER}\end{array}$ & $\begin{array}{c}4 \mathrm{~dB}^{*} 10^{-8} \\
\mathrm{BER}\end{array}$ & -22 & -14 & -12 & 83 & 81 & 3.56 \\
\hline 60 & $\begin{array}{c}14 \mathrm{~dB} \\
* 10^{-2} \mathrm{BER}\end{array}$ & $\begin{array}{c}16 \mathrm{~dB} \\
* 10^{-2} \mathrm{BE} \\
\mathrm{R}\end{array}$ & -22 & -12 & nil & 84 & 80 & 4.59 \\
\hline
\end{tabular}

Table.2 Performance of Proposed Method

The table. 2 above presents the results obtained for optical fibers of three different lengths in term of the launched optical power, received optical power and the transmission rates achieved. The optical delay line adjusted in the proposed system in the single path ensures the transmission rates of the optical signal. 
Journal of Electronics and Informatics (2019)

Vol.01/ No. 02

Pages: $107-116$

http://www.irojournals.com/iroei/

DOI: https://doi.org/10.36548/jei.2019.2.006

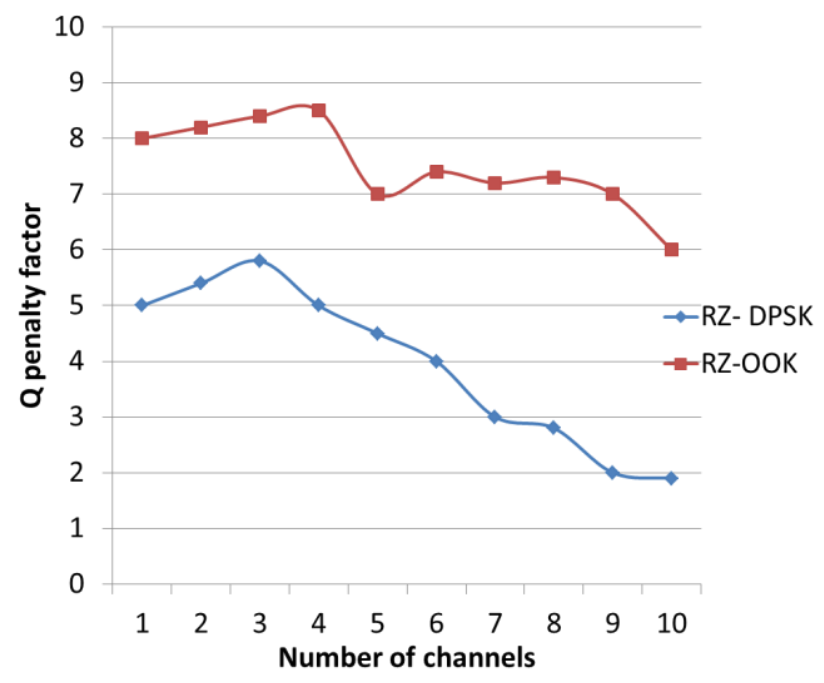

Figure.4 Q penalty Channel Cross Talk Suppression

The cross talk levels are examined and to identify the robustness of the RZ -DPSK for the multiple channels and the results observed are presented in the figure. 4 above. The figure. 4 representing the $q$ factor penalty of the channels used in the communication shows that the return zero-DPSK is best compare to the Return Zero-OOK for suppressing the cross talks and improving the work quality. It was also observed that the as the fiber length increased the performance of the optical cable deteriorated progressively.

\section{CONCLUSION}

The fiber optic transmission is widely and increasingly used instead of the metal wires due to is increased efficiency and the high transmission capacity. The proposed system for enabling a high speed communication in the MIMO based OFC utilizes the LiNbO3 to up convert the signal using different carrier frequency generated using the dual arm to transmit multiple signals using single optical sources without being affected by the crosstalk by the employment of the RZ-DPSK .The proposed system supports multiple wireless signal transmission at a higher speed using the single optical source without crosstalk's. The experimental results obtained prove that the novel techniques provide a communication system that is efficient. In future the paper would try increasing the data transmitted per second by utilizing the division multiplexing based on mode 
Journal of Electronics and Informatics (2019)

Vol.01/ No. 02

Pages: $107-116$

http://www.irojournals.com/iroei/

DOI: https://doi.org/10.36548/jei.2019.2.006

\section{References}

[1] Al Amin, Abdullah, An Li, Simin Chen, Xi Chen, Guanjun Gao, and William Shieh. "Dual-LP 11 mode 4x4 MIMO-OFDM transmission over a two-mode fiber." Optics Express 19, no. 17 (2011): 1667216679.

[2] Lee, Jong-Hun, Yun-Kyung Oh, Sang-Il Lee, Seo-Won Kwon, Jong-Hwa Lee, and Yun-Je Oh. "Access point for constructing optical fiber-based high-speed wireless network system." U.S. Patent 7,349,633, issued March 25, 2008.

[3] Hsu, Rick CJ, Alireza Tarighat, Akhil Shah, Ali H. Sayed, and Bahram Jalali. "Capacity enhancement in coherent optical MIMO (COMIMO) multimode fiber links." IEEE Communications letters 10, no. 3 (2006): 195-197.

[4] Fan, Shu-Hao, Hung-Chang Chien, Arshad Chowdhury, and Gee-Kung Chang. "Spectrally efficient 60GHz xy-MIMO data transport over a radio-over-fiber system for gigabit wireless local area networks." In 2010 IEEE Global Telecommunications Conference GLOBECOM 2010, pp. 1-4. IEEE, 2010.

[5] Shao, Yufeng, and Nan Chi. "A novel scheme for seamless integration of RZ-DPSK-DWDM optical links with MIMO-OFDM system." Microwave and Optical Technology Letters 54, no. 7 (2012): 16761679.

[6] Zhao, Yisheng, $\mathrm{Xi} \mathrm{Li}$, and Hong Ji. "Radio admission control scheme for high-speed railway communication with MIMO antennas." In 2012 IEEE International Conference on Communications (ICC), pp. 5005-5009. IEEE, 2012.

[7] Kuruvila, Diya Ann, and Jennifer S. Raj. "Dynamic Adaptive Topology Control in Highly Mobile Environment."

[8] Ananthi, J. Vijitha, and Jennifer S. Raj. "A Peer to Peer Overlay Approach for Topology Maintenance in Wireless Networks."

[9] Jyothirmai, P., and Jennifer S. Raj. "Secure interoperable architecture construction for overlay networks." In 2015 International Conference on Innovations in Information, Embedded and Communication Systems (ICIIECS), pp. 1-6. IEEE, 2015.

[10] Kumar, R. Praveen, and S. Smys. "A novel report on architecture, protocols and applications in Internet of Things (IoT)." In 2018 2nd International Conference on Inventive Systems and control (ICISC), pp. 1156-1161. IEEE, 2018.

[11] Raj, Jennifer S., and R. Harikumar. "A new distributed architecture for connectivity analysis in wireless networks." Procedia Engineering 30 (2012): 394-401.

[12] Anguraj, Dinesh Kumar, and S. Smys. "Trust-based intrusion detection and clustering approach for wireless body area networks." Wireless Personal Communications 104, no. 1 (2019): 1-20. 
Journal of Electronics and Informatics (2019)

Vol.01/ No. 02

Pages: 107-116

http://www.irojournals.com/iroei/

DOI: https://doi.org/10.36548/jei.2019.2.006

[13] Ho, Chun-Hung, Rakesh Sambaraju, Wen-Jr Jiang, Tsung-Hung Lu, Chih-Yun Wang, Hejie Yang, WeiYuan Lee et al. "50-Gb/s radio-over-fiber system employing MIMO and OFDM modulation at $60 \mathrm{GHz."}$ In Optical Fiber Communication Conference, pp. OM2B-3. Optical Society of America, 2012.

[14] Thomsen, Benn C. "MIMO enabled $40 \mathrm{~Gb} / \mathrm{s}$ transmission using mode division multiplexing in multimode fiber." In Optical Fiber Communication Conference, p. OThM6. Optical Society of America, 2010 . 